\title{
The Practice of 'Three Competitions, Three Training and Three Combination' as Training Mode for Innovative Talents
}

\author{
Wang Xi, Liu Jian", Zhang Xiaojun, Xue Zhengkun \\ School of Mechanical Engineering and Automation, University of Science and Technology Liaoning, Anshan, China \\ Email address: \\ wx1870@yeah.com (Wang Xi), 13941214957@163.com (Liu Jian) \\ ${ }^{*}$ Corresponding author
}

To cite this article:

Wang Xi, Liu Jian, Zhang Xiaojun, Xue Zhengkun. The Practice of ‘Three Competitions, Three Training and Three Combination' as Training Mode for Innovative Talents. Science Journal of Education. Vol. 8, No. 2, 2020, pp. 56-61. doi: 10.11648/j.sjedu.20200802.14

Received: April 16, 2020; Accepted: May 26, 2020; Published: June 3, 2020

\begin{abstract}
In order to cultivate innovative talents, the research group takes the reform of the training mode of mechanical innovative talents as the focus, integrating innovation and entrepreneurship competition and scientific research into the daily professional teaching, so as to construct a new trinity education mode named 'three competitions, three training and three combinations'. On the basis of this model, starting from the concept of 'case-based, project-based and problem-based', we focus on cultivating student's critical thinking, and adopts a variety of teaching methods such as flipped classroom, divided classroom, online and offline as well as in-class and out-of-class, so as to achieve teaching interaction in a real sense. It achieves the unification of professional teaching, scientific research training and innovation and entrepreneurship education. Through the means of reform and examination, student's various abilities are evaluated from multiple perspectives and from multiple directions, which can objectively reflect student's learning situation and student's engineering application ability, so that student's innovation ability and comprehensive quality have been improved. In addition, the innovation and entrepreneurship thinking training and innovation competition results are introduced into the implementation of the teaching reform to provide new ideas and new ways for the cultivation of innovative and high-quality talents in colleges and universities.
\end{abstract}

Keywords: Innovative Talents, Professional Education, Practice

\section{Introduction}

' 333 ' is a training-mode theory which stands for 'three kinds of different competitions, training methods and combination modes'. This theory is gradually established, perfected and implemented according to the experience of various innovation and entrepreneurship competitions participated by college students. In order to further deepen the reform of innovation and entrepreneurship education in colleges and universities [1], we build a new carrier of innovation and entrepreneurship education by taking 'three kinds of different competition, training and combination" as the focus of the cultivation mode of mechanical innovation and entrepreneurship talents, and combine innovation and entrepreneurship education with the teaching of mechanical courses.

We will revise the teaching syllabus and prepare teaching plans to adapt to the concept of innovation and entrepreneurship, and introduce the latest advanced scientific research achievements into the classroom. The reform of the examination mode, the adoption of project-driven and question-guided courses and extracurricular teaching interaction mode, the concept of innovation and entrepreneurship education throughout the whole process of talent training, so that students can be comfortable in employment, when starting a business with confidence.

\section{Connotation of Training-Mode}

As shown in figure 1, the implementation of the talent cultivation mode of 'three kinds of different competitions, training methods and combination modes ' is mainly based on the experience of college students participating in various innovation and entrepreneurship competitions, which is gradually established and improved [2]. 


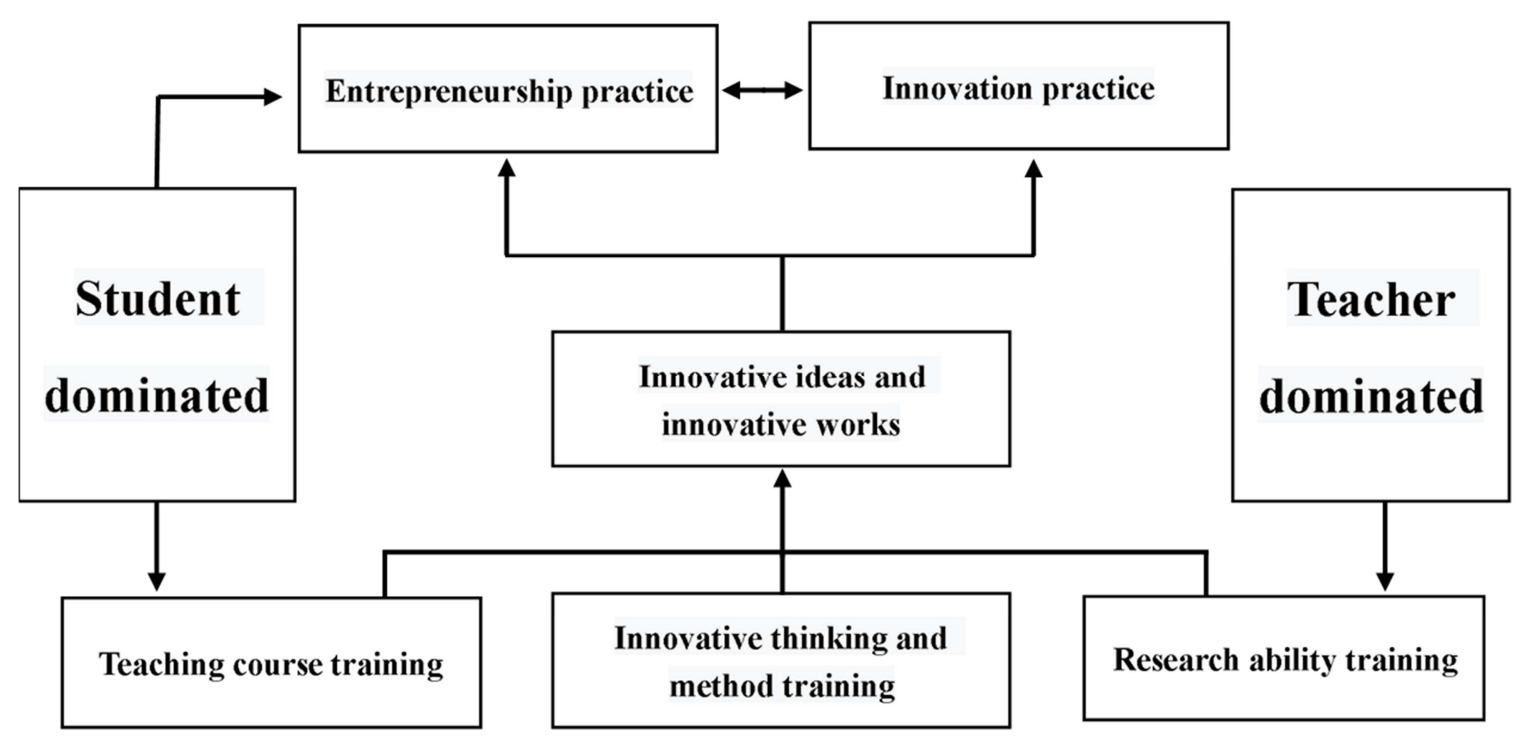

Figure 1. Block diagram of talent training mode.

"Three competitions" refers to the mechanical innovation design competition, innovation and entrepreneurship project training competition and Creative Engineering Design Competition. College students are the most innovative group. With the innovation competition as the carrier, to create a platform to cultivate students' innovative spirit, innovation and entrepreneurship ability, so that students can grow through the innovation competition. In addition, students can be encouraged to continue to engage in innovation and entrepreneurship activities by winning awards in the competition.

"Three training" mainly includes course training, innovative thinking and methods training and scientific research training. The three are mutually integrated and complementary. Among them, "course training" refers to the content covered by the classroom teaching plan. "Innovative thinking and methods training" refers to the practice of innovation and entrepreneurship outside the classroom, such as innovation competition. "Research training" refers to the scientific research enlightenment that students engage in through the innovation and entrepreneurship training program and by joining the teachers' research team.

"Three combination" refers to the combination of curriculum training and innovation competition, innovation competition and research training, and research training and curriculum training. First of all, the innovation competition can enhance students' awareness of innovation, is a special training beyond the classroom teaching, but also can promote the course training. Besides, scientific research training is a deeper level of training on the basis of innovation competition, which can cultivate students' scientific research literacy and innovation consciousness. In the end, the scientific research training can be returned to the course training, and the three can complement each other and be short of one. The ultimate purpose is to encourage students to study independently and gradually grow into talents with innovative ability. In addition, by organizing students to participate in all kinds of innovation competition activities, the topic of innovation and entrepreneurship training program can be established from them, which complement and support each other.

In the "333" talent training mode, students are the main body of "three kinds of different competitions, training methods and combination modes ". In this training mode, the concept of "students as the main body, teachers as the leading role" should be actively advocated. The core of "three training" always emphasizes that students are the main body of training activities, and teachers' work is mainly to assist and guide. From the innovation idea is put forward, the two-dimension drawings to the engineering drawing, and the three-dimension dynamic simulation of Solidworks, raw materials procurement, model processing, manufacturing, assembly and debugging of the whole process of innovation activities, rely on their own. Teachers have to guide their student, points out the problems and correct them in order to help the students to solve the problems. Finally, the students will grow in the process of problem solving, students innovative thinking and the ability to truly get training and exercise.

\section{Research Technical Route}

The research process centering on innovation and entrepreneurship education is to introducing innovative results into the revision of teaching syllabus and the writing of innovative teaching plans and teaching material, conduct classroom teaching through project-driven and leading question methods, and examination reform, so as to realize the real interactive teaching. The research technology road map is shown in Figure 2. 


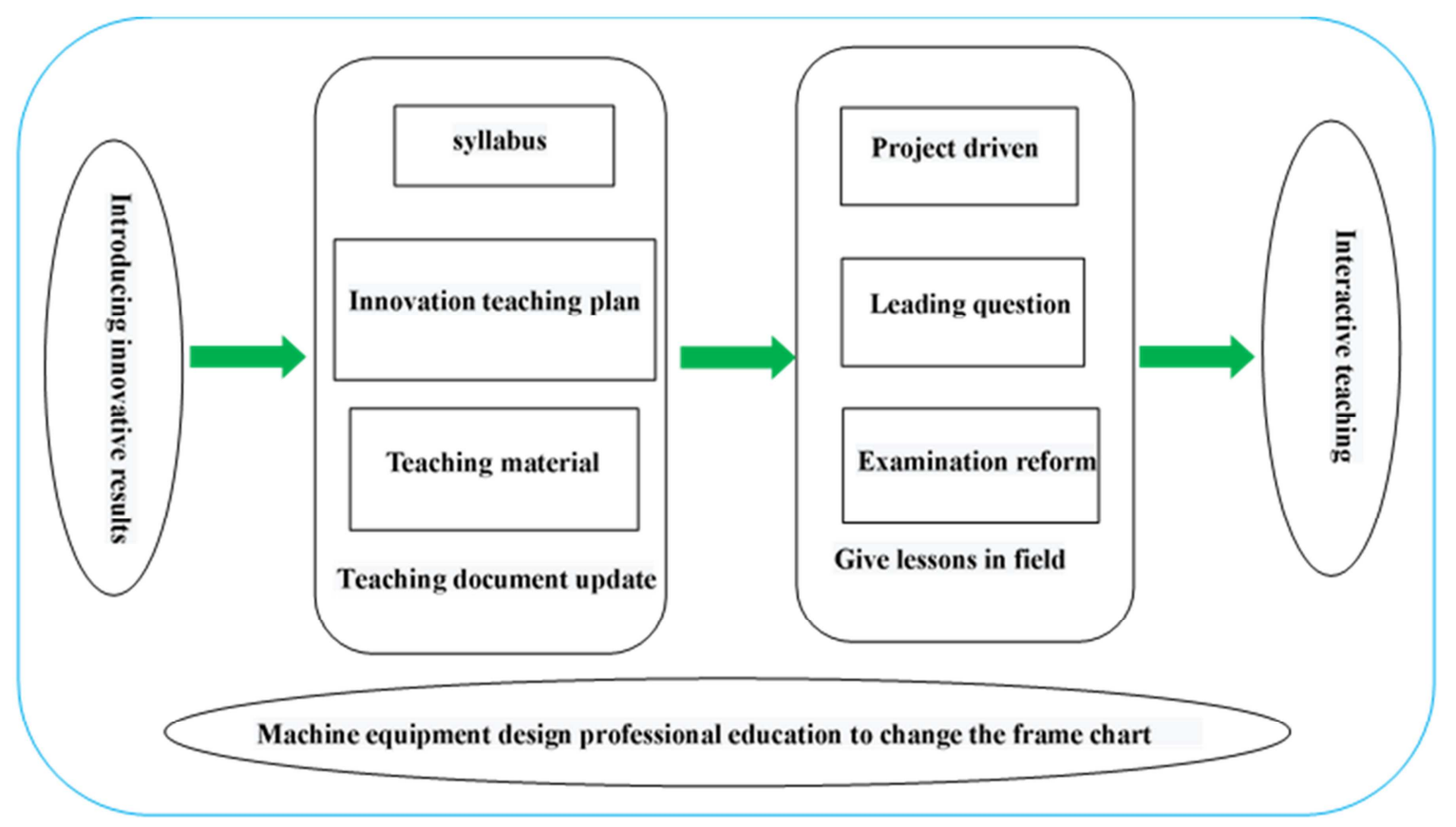

Figure 2. Research technology roadmap.

\section{Program research Characteristics}

Innovation and entrepreneurship education is a form of education that focuses on cultivating students' innovative consciousness and entrepreneurial ability [3]. Innovation and entrepreneurship are inseparable. Innovation is the foundation and core of entrepreneurship, emphasizing the originality of "get rid of the stale and bring forth the fresh", while entrepreneurship is an important form of innovation, emphasizing the theory of innovation into practice, and creating new undertakings.

1. The systematic improvement of critical thinking affects the professional quality, innovation ability and practical ability of college students [4], which has become the core concern of the reform and development of higher education. Individuals with critical thinking are exactly the needs of the society, which requires us to pay more attention to the cultivation of students critical thinking in the teaching process instead of just focusing on the teaching of specific teaching contents, which is also the fundamental of the cultivation of innovative talents. The cultivation of critical thinking ability is a systematic project, which requires the establishment of interdisciplinary and cross-disciplinary courses and high-level research-based learning activities, so as to improve students critical thinking ability and learning quality based on the methods of autonomy, cooperation and discussion.

2. Combine innovation and entrepreneurship education with mechanical design courses. As a new educational concept and mode, innovation and entrepreneurship education has become a hot topic in academia. To encourage college students innovative undertaking education reform, strengthen the ability oriented personnel training mode of teaching reform as an opportunity, in all kinds of innovative entrepreneurship practice activities as the carrier, actively explore innovation entrepreneurship education reform and development, strive to create the "integration of comprehensive, integrated," education platform, to strengthen the students innovative consciousness and practice ability and the cultivation of entrepreneurial quality [5].

3. Split the classroom teaching into half is a new teaching method. It's key innovation is the 'compartment discussion', which is to stagger teachers teaching time and students discussion time. 'Interval discussion' is a key innovation of the divided class. Half of the class time is allocated to the teacher's teaching and half to the students discussion. The students discussion is the content taught by the teacher in the last class.

4. Flipped classroom can also be translated as "invertedclassroom". It is a complete subversion of the traditional classroom teaching structure and teaching process based on printing technology, which will lead to a series of changes in the role of teachers, curriculum model, management model and so on. Under this teaching mode, the time in and out of the classroom will be readjusted, and the decision of learning will be transferred from teachers to students. With precious time in the classroom, students can focus more on active project-based learning, and work together to solve the challenges of localization or globalization and other problems facing the real world, so as to gain a deeper understanding [6].

\section{Research on Implementation Methods}

1. Introduce the latest scientific and technological achievements.

In rolling theory of mechanical design course, today's most advanced rolling mill, straightening machine, shearing machine, flying shear machine, coiling machine, rolling 
machine, and continuous casting machine, such as converter, system of blast furnace smelting machinery, showed by multimedia teaching to the students. let students understand the latest developments in the field of, walk at the forefront of science, cultivate students' innovative thinking and innovative spirit.

2. Expand the teaching contents with case and project driving as the core.

From "based on case, based on the project and based on the problem, the project driven" concept as a starting point, guided by the engineering case, the mill, straightening machine, shearing machine, rolling mills of typical equipment such as flying shear and the system of blast furnace, converter tilting mechanism of smelting equipment such as [7], parameter calculation and structure design and production of equipment failure and parts of fracture accident as a typical case is introduced into classroom teaching. Desides, the organic combination of theory and practice, so that students deeply feel that the study is useful, and for the later comprehensive innovative design and graduation design to lay a solid foundation.

3. The course teaching is carried out in the form of problem orientation, that is, split the lecture into half.

Split the lecture into half is a new teaching method. Its key innovation is the "compartment discussion", which is to stagger teachers' teaching time and students' discussion time. A divided class consists of three parts: teacher's class teaching, students' self-study after class, and classroom discussion between teachers and students. This new teaching method attaches great importance to the process of knowledge internalization, emphasizes the process evaluation of learning outcomes, and considers that the selection of teaching materials is one of the factors that directly affect the teaching effect. Front-line teachers from a number of colleges and universities have already practiced the divided classroom, and the results of investigation and research prove that this method can improve the teaching efficiency and students' learning enthusiasm. It is expected to become a university classroom with Chinese characteristics [8-9].

Educator Wei Du believes that "thinking as the center of learning" is an important condition for effective learning. Thinking is identifying the relationship between what we are trying to do and the outcome that results from that attempt. The process of preparing students for discussion is also a process of thinking. Students come to class prepared, avoid formal discussion, significantly improve the quality of discussion, active classroom atmosphere, enhance students' learning enthusiasm and initiative.

4. Internet-based "flipped classroom" teaching mode.

The Internet, especially the mobile Internet, has given rise to the "flipped classroom" teaching model, which is part of the big education movement. It overlaps with online and offline hybrid learning, exploratory learning, and other teaching methods and tools in meaning [10-11]. All for the purpose of making learning more flexible and active and enabling students to participate more. In the Internet age, students can learn a wealth of online courses through the Internet, without having to go to school to be taught by teachers. Teachers no longer take up class time to teach information that students need to learn on their own before class starts. They can watch video lectures, listen to podcasts, read enhanced e-books, discuss with other students on the Internet, and consult required materials at any time. Besides, teachers have more time to communicate with everyone. After class, students independently plan the learning content, learning rhythm, learning style and the way of presenting knowledge, while teachers adopt the teaching method and the collaborative method to meet students' needs and promote their personalized learning, whose goal is to enable students to obtain more real learning through practice.

5. Online teaching.

In 2020 due to the global will be coronavirus outbreak, the influence of school can't start as scheduled. Although students can't back to school in class, the suspension is not closed, the Internet reflects a big advantage, Ding Talk, Superstar, Rain Classroom Tree of knowledge and Tencent Meeting [12, 13], provides online teaching conditions for education workers. Teachers in our research group make full use of these platforms to conduct online teaching and ensure that the school's teaching work is carried out as scheduled.

6. Reform the examination mode

The assessment method of "daily performance, experiment, project training, paper, written examination, comprehensive reply" is adopted [14]. In addition, it also increases the proportion of practical links in the examination, takes into account the students' usual classroom performance, and strengthens the process management. This kind of examination method can evaluate the students' various abilities from many aspects and can reflect the students' learning situation more objectively. It is also conducive to the improvement of students' engineering application ability, innovation ability and comprehensive quality. For students who publish papers, apply for patents, and participate in the innovation and entrepreneurship training program, credit awards or partial assessment can be adopted. This will help stimulate students' enthusiasm for innovation and entrepreneurship, and make the assessment method more flexible and varied.

7. Realize multiple modes of interaction in and out of class

A variety of teaching modes are adopted in in-class and out-of-class teaching as well as online and offline mixed teaching. Flexible and diverse teaching methods such as case method, project-driven, heuristic, questioning and discussion are adopted in class to improve students' learning initiative. After class, we make full use of the advantages of the Internet, maintain constant communication with students through QQ, WeChat, Ding Talk and Superstar. Seting up public accounts of steel rolling machinery and smelting machinery [15], regularly publish popular science articles and the latest literature in this field, interact with students, let students learn more.

\section{Practical Effect}

Taking the course of "steel rolling machinery design 
theory" as an example, the first semester of the 2019-2020 academic year began to try to carry out the flipped classroom teaching method, flip the learning process, and implement the online and offline hybrid teaching, so that students can learn knowledge outside the classroom and internalize knowledge in the classroom. By using the teaching platforms of "cloud class" and "super star learning link" to release learning tasks and related learning materials in advance after class, students can conduct independent online learning through the app on the mobile phone terminal. Students are required to upload preview notes and display good preview notes in class to attract more students to preview before class. Conduct online test in the first 10 minutes of class to check the students preview results; Next, I will explain the knowledge points with high error rate in detail, arrange exercises in class, and ask students to upload them to class in class. Then, I will randomly select students answers to make comments on the spot by means of mobile phone screen projection, and then I will take the way of teachers and students joint comments to strengthen the understanding of important knowledge points again. Next is the student presentation: some students summarize the key points of the class, some students draw a chapter of the mind map, Finally, assign the preview task and the corresponding homework for the next lesson. Students will accumulate certain experience values on the teaching app after completing a task before class and after class, and these experience values will be converted into students scores at the end of the day. After a semester's experiment, students class participation is improved, the interaction between teachers and students is good, and the failure rate is reduced.

In addition, the research group actively encourages students to participate in extracurricular innovative academic activities and has achieved fruitful results. 7 successively to guide the national college students' innovative entrepreneurial projects, 10 provincial innovative entrepreneurial projects, 12 field projects, guide students to get three silver prizes in Creative Engineering Design Competition (CEDC), take part in many kinds of mechanical innovation contest, won 1 national first prize, 2 national second prize, 8 provincial first prize and 3 provincial second prize. Our students published 3 scientific and technological papers, one of which is included in EI, reflecting the achievements of teaching reform.

The project team members actively carried out the research work of teaching reform around the subject, and won the first prize of provincial education reform achievement and the second prize of university-level education reform achievement respectively. It has already applied for 2 provincial educational reform projects and 2 university-level teaching materials projects. We completed 2 provincial-level educational reform projects and 10 university-level educational reform projects. Completed 2 sets of self-made equipment, and published 6 teaching reform papers.

Three invention patents and eight utility model patents were granted. All of the above can fully reflect the effect of teaching reform.

\section{Conclusion}

To sum up, the mode of "three competitions, three training and three combination" is the exploration of our research group in the reform of mechanical innovative talent's education system. This paper studies the connotation, technical route, program features and specific implementation methods of the "three competitions, three training and three combination" mode, and summarizes the practical results. Practice has proved that it, for cultivating professional talents with innovative spirit and strong scientific research ability, is of great significance to integrate innovation and entrepreneurship competition and scientific research training into specialized courses and practical teaching, and to build a new educational carrier linking education and teaching with innovation and research.

\section{The Educational Reform Project}

1. 2018, University of Science and Technology Liaoning, The key project of innovation and entrepreneurship education and teaching research: the construction and practice of the carrier of innovation and entrepreneurship education with the focus of "three kinds of different competitions, training methods and combination modes"

2. 2016 Liaoning provincial undergraduate education reform project general project "exploration on the cultivation mode of mechanical innovation and entrepreneurship talents based on practice innovation" (Liaoning Education development [2016.23])

\section{References}

[1] Ministry of education, PRC. Implementation opinions of the general office of the state council on deepening innovation and entrepreneurship education reform in institutions of higher learning $[\mathrm{EB} / \mathrm{OL}]$. Website of ministry of education, http://old.moe.gov.cn/publicfiles/business/htmlfiles/moe/moe 1778/201505/187212.html, 2017-06-18.

[2] Wang Xi. construction of the talent cultivation model of "three competitions, three trainings and three combinations" in mechanical major [J]. China metallurgical education, 2017 (6): 61.

[3] Dong Mingliang. Research on cultivation of innovation ability of mechanical talents [J]. Education science, 2015 (11): 234.

[4] Ma peipei. On critical thinking and its cultivation [J]. Wisdom, 2020 (6): 240.

[5] Chen kuiqing. The mode and realization path of the integration of entrepreneurship education and professional education $[\mathrm{J}]$. China higher education, 2014 (22): 48-50.

[6] FuYanli. A review of flipped classroom research [J]. Modern communication, 2020 (4): 191-192.

[7] Zhang Xiaojun. Teaching reform of mechanical design major under the background of innovation and entrepreneurship $[\mathrm{J}]$ science and technology innovation guide, 2019 (11): 198-199. 
[8] Sun Shuangshuang. Exploration and practice of engineering mechanics in divided classes $[\mathrm{J}]$ education and teaching forum, 2020 (7): 174-175.

[9] Yu Xiaojun. College students professional ability cultivation based on the mode of divided classes $[\mathrm{J}]$ Chinese and foreign entrepreneurs $[\mathrm{J}]$ Chinese and foreign entrepreneurs, 2020 (9): 171-172.

[10] Bi Rengui. The integration of Internet and flipped classroom in the teaching of mechanical design course $[\mathrm{J}]$. Time automotive, 2019 (13): 53-54.

[11] Yang Junshi. Research on flipped classroom teaching model based on super star learning channel [J] Chinese and foreign entrepreneurs, 2020 (8): 211.

[12] Qi Zhimin. Research and application of online and offline hybrid computer teaching $[\mathrm{J}]$. Computer products and circulation, 2020 (03): 145.
[13] Song Xiaoming. Information-based teaching reform of material forming and technology course of machinery manufacturing major in higher vocational colleges based on blue ink cloud class [J]. Journal of chengde petroleum college, 2008, 20 (04): $78-81$

[14] Zhou Guilian. Curriculum examination reform and practice in higher vocational education -- a case study of jilin university of chemical technology $[\mathrm{J}]$. Journal of jilin university of chemical technology, 2017, 34 (06): 25-28.

[15] Liu Jun. Research on the teaching mode of strengthening practice in general higher engineering education -- a case study of cement matrix composites and engineering measurement courses in civil engineering major [J]. Sichuan building materials, 2020, 46 (02): 229-230. 